\title{
Carboxyhaemoglobin in women exposed to different cooking fuels
}

\author{
D Behera, S Dash, S P Yadav
}

\begin{abstract}
Blood carboxyhaemoglobin levels were estimated by double wavelength spectrophotometry in non-smoking women living in Chandigarh and its environs and related to the cooking fuel they used. Twenty nine used kerosene, 28 biomass fuel, and 30 liquified petroleum gas; the 27 control subjects had not done any cooking for seven days. The carboxyhaemoglobin concentrations were significantly higher in the women using the three types of fuel (mean (SEM) concentration $7.52 \%(0.67 \%)$ for kerosene, $15.74 \%(0.83 \%)$ for biomass fuel, and $17 \cdot 16 \%(0 \cdot 62 \%)$ for liquified petroleum gas, compared with $3.52 \%(0.33 \%)$ in the control subjects. It is concluded that cooking with any of the three fuels causes indoor air pollution. It is important to have better designed houses with adequate ventilation and stove vents that are cleaned regularly if pollution is to be reduced.
\end{abstract}

Smoke emission from domestic fuels is a major source of indoor air pollution, especially in the rural communities of developing countries. The emissions contain pollutants that adversely affect health. ${ }^{1-3}$

Common fuels used for cooking and other domestic purposes in India include biomass fuel (cowdung cake and other manures, agricultural wastes, firewood, etc), kerosene oil, liquified petroleum gas, and coal lighted Angithi. The biomass fuel is used on chullas made of earth and built inside the kitchen. The biomatter (cowdung and other manures) is dried in the sun and stored before use. Kerosene oil is used in pressure and wick stoves. Liquified petroleum gas is stored in cylinders and connected to a metal stove with burners. These cooking devices are in widespread use throughout India, where they produce significant morbidity and mortality, ${ }^{45}$ as reported from other countries. ${ }^{6-10}$ The pollutants include several known carcinogens, such as benzpyrene, and toxic substances such as carbon monoxide, sulphur dioxide, nitrogen dioxide, formaldehyde, asbestos fibres, microorganisms, and aeroallergens. ${ }^{11-14}$ In an earlier study we found high blood carboxyhaemoglobin concentrations after acute exposure to smoke from biomass fuel. ${ }^{15}$ The present study extends these observations, documenting the extent of indoor air pollution produced with various fuels, commonly used for cooking in India, including kerosene, liquified petroleum gas, and biomass fuel.

\section{Methods}

The study was carried out on women exposed to different cooking fuels residing in Chandigarh and adjoining areas. Women using gas for cooking mostly belonged to the middle socioeconomic class and those using kerosene and biomass fuel belonged to the lower socioeconomic class. Women who smoked and those with any kind of respiratory disease were excluded from the study. Subjects were selected at random and after giving informed consent were asked for a detailed cooking history. The type of fuel used, average duration of cooking, and number of years of cooking were noted. The control group was selected from hospital attendants who had done no cooking for seven days. An exposure index (EI) was calculated by multiplying the number of years of cooking and the average hours of cooking per day. A single spot heparinised sample of venous blood was drawn within two hours of exposure and put into an airtight plastic phial for estimation of blood carboxyhaemoglobin concentration. The sample was also used to estimate packed cell volume.

\section{ANALYTICAL PROCEDURE FOR ESTIMATION OF} CARBOXYHAEMOGLOBIN

Blood carboxyhaemoglobin concentrations were measured by double wavelength spectrophotometry of absorbance difference. ${ }^{16}$ The sensitivity and reproducibility of the method in our laboratory has been described. ${ }^{15}$ Carbon monoxide was freshly prepared from formic acid and sulphuric acid for each estimation. To determine the wavelength pair, fresh blood was diluted with $\mathrm{Na}_{2} \mathrm{~S}_{2} \mathrm{O}_{4}$ as described. ${ }^{15}$ The absorbance was read by spectrophotometer (Spectronic 106 Ambala Sarabhai Enterprises Ltd, Ahmedabad, India) every 5 $\mathrm{nm}$ from $500 \mathrm{~nm}$ up to $600 \mathrm{~nm}$ so that two wavelengths, on the extremes of the wavelength range, could be found at which the sample had minimum absorbance difference. For this study the two wavelengths were 530 and $585 \mathrm{~nm}$.

\section{LINEARITY AND REPRODUCIBILITY OF THE} METHOD

Ten serially diluted samples of $0-100 \%$ carboxyhaemoglobin were measured and showed good linearity up to $90 \%$ carboxyhaemoglobin. Reproducibility for six measurements at every dilution had a coefficient of variation of less than $1 \%$ at $20-100 \%$ carboxyhaemoglobin and of $2-8 \%$ at $10 \%$ and below.

The normal control range for carboxy- 
Table 1 Mean (SEM) age, time interval between exposure and sampling (TI), carboxyhaemoglobin (CoHb), exposure index (EI), and packed cell volume (PCV) in the subjects studied

\begin{tabular}{|c|c|c|c|c|c|c|}
\hline Fuel & $\begin{array}{l}\text { No of } \\
\text { subjects }\end{array}$ & Age (y) & $T I(\min )$ & $\mathrm{CoHb}(\%)$ & $E I$ & $P C V(\%)$ \\
\hline $\begin{array}{l}\text { None (controls) } \\
\text { Kerosene } \\
\text { Biomass } \\
\text { Liquified petroleum gas }\end{array}$ & $\begin{array}{l}27 \\
29 \\
28 \\
30\end{array}$ & $\begin{array}{l}27.66(1.31) \\
29.83(1.39) \\
26.25(0.83) \\
32.93(1.69)\end{array}$ & $\begin{array}{l}\overline{42} \cdot 41(7 \cdot 31) \\
49 \cdot 82(7 \cdot 84) \\
51 \cdot 33(7 \cdot 82)\end{array}$ & $\begin{array}{r}3.52(0 \cdot 33) \\
7 \cdot 49(0 \cdot 67) \\
15 \cdot 74(0 \cdot 83) \\
17 \cdot 16(0 \cdot 62)\end{array}$ & $\begin{array}{l}- \\
33 \cdot 51(3 \cdot 82) \\
36 \cdot 21(3 \cdot 38) \\
37 \cdot 93(4 \cdot 52)\end{array}$ & $\begin{array}{l}39 \cdot 44(0.77) \\
38 \cdot 83(0.64) \\
38 \cdot 11(0 \cdot 86) \\
42 \cdot 77(0.76)\end{array}$ \\
\hline Analysis of variance: & $\begin{array}{l}\mathbf{F} \\
\mathbf{p}\end{array}$ & $\begin{array}{l}4.667 \\
0.0041\end{array}$ & $\begin{array}{l}0.39 \\
0.6782\end{array}$ & $\begin{array}{r}102.494 \\
0.00001\end{array}$ & $\begin{array}{l}1 \cdot 147 \\
0 \cdot 3352\end{array}$ & $\begin{array}{l}7.55 \\
0.0001\end{array}$ \\
\hline
\end{tabular}

haemoglobin was $0-5 \%$. The mean value for the control subjects (10 samples) at the same time was $3 \cdot 29 \%$ (SD $0 \cdot 27 \%$ ).

Analysis of variance was used to compare the values of carboxyhaemoglobin between the groups and Student's $t$ test and the correlation coefficient as required. The data were analysed by means of a Statgraphics V 3.0 on a IBM PC XT computer.

\section{Results}

Of the 114 women studied, 29 had been exposed to kerosene, 28 to biomass fuel, and 30 to liquified petroleum gas, and 27 had done no cooking in the last seven days. The mean age, exposure index, carboxyhaemoglobin concentrations, and timing of blood sampling are shown in table 1 . The mean age of the subjects was greater in the liquified petroleum gas users. The exposure index did not differ significantly between the three groups of fuel users, nor did the time interval between the last exposure and blood sampling $(p=0.67)$. The subjects exposed to the three different fuels had significantly higher carboxyhaemoglobin levels than the control subjects $(p<0.001)$. Liquified petroleum gas users had the highest values, followed by biomass and kerosene users. Packed cell volume was also higher in the liquified petroleum gas users, and lower in the other two groups of fuel users, than in the controls. There was a positive correlation between carboxyhaemoglobin concentration and packed cell volume in the three groups of fuel users but not in the control group (table 2). The carboxyhaemoglobin concentration and the time interval between the last exposure and blood sampling showed a negative correlation in all three groups, though this was significant only for the women using biomass fuel and liquified petroleum gas. Exposure index was not correlated with packed cell volume. Carboxy- haemoglobin was lower in women whose sample was taken 60 minutes or more after the last exposure. Although carboxyhaemoglobin tended to rise with exposure index in all three fuel groups, the trend was significant only in those using liquified petroleum gas (mean (SD) concentration $14.00 \%(5 \cdot 29 \%)$ for exposure index $20-39$ and $18.7 \%(2.985 \%)$ for 40 and over; $p=0.033$ ).

\section{Discussion}

The blood carboxyhaemoglobin concentrations in non-smoking healthy subjects exposed to three different types of cooking fuel were two to five times higher than those in a non-smoking healthy control population; the difference was significant. The carboxyhaemoglobin values are similar to those observed in chronic bidi and cigarette smokers (unpublished data). The relatively high mean carboxyhaemoglobin concentration among healthy controls of $3.52 \%$ was possibly because of exposure to environmental smoke and pollution. Additionally, in the method used for carboxyhaemoglobin estimation the coefficient of variation was nearly $\mathbf{6 . 8 \%}$ for carboxyhaemoglobin concentrations of $5.0 \%$ and below.

Biomass fuels are used largely in the developing countries and predominantly in the rural areas. They are composed of complex organic matter, vegetable proteins, and carbohydrates incorporating carbon, nitrogen, oxygen, hydrogen, and certain other elements in trace amounts. Chronic bronchitis and cor pulmonale are reported to be associated with the use of this fuel in non-smoking rural women in India and Nepal. ${ }^{4-6}$ The high concentrations of carboxyhaemoglobin in biomass fuel users conform with our findings in a preliminary study. ${ }^{15}$ Dary $e t a^{17}$ in a study from rural Guatemala found raised blood carboxyhaemoglobin concentrations in women working in poorly ventilated kitchens with toxic concentrations of

Table 2 Correlation of different measurements

\begin{tabular}{|c|c|c|c|c|c|}
\hline Fuel & $\begin{array}{l}\text { No of } \\
\text { subjects }\end{array}$ & $C o H b v E I$ & $C o H b v P C V$ & CoHb v TI & $E I$ ข $P C V$ \\
\hline None (controls): $\mathbf{r}$ & 27 & - & $\begin{array}{l}0 \cdot 10 \\
0 \cdot 34\end{array}$ & - & - \\
\hline Kerosene: $\mathbf{r}$ & 29 & $\begin{array}{l}0.12 \\
0.52\end{array}$ & $\begin{array}{l}0.403 \\
0.03\end{array}$ & $\begin{array}{c}-0.165 \\
0.39\end{array}$ & $\begin{array}{l}0.1099 \\
0 \cdot 57\end{array}$ \\
\hline Biomass: $\mathbf{r}^{\mathbf{p}}$ & 28 & 0.07 & 0.457 & -0.528 & -0.133 \\
\hline $\mathbf{p}$ & & 0.71 & 0.014 & 0.0039 & 0.50 \\
\hline Liquified petroleum gas: $\mathbf{p}$ & 30 & $\begin{array}{l}0.389 \\
0.033\end{array}$ & $\begin{array}{l}0.5089 \\
0.004\end{array}$ & $\begin{aligned}-0.46 \\
0.0105\end{aligned}$ & $\begin{array}{r}-0.05 \\
0.75\end{array}$ \\
\hline
\end{tabular}

$\mathrm{CoHb}-$ carboxyhaemoglobin; $\mathrm{EI}-$ exposure index; $\mathrm{PCV}$-packed cell volume; $\mathrm{TI}$-time interval between last exposure and blood sampling. 
environmental carbon monoxide (30-50 ppm).

In the case of low pressure petroleum gas stoves carboxyhaemoglobin concentrations were surprisingly high. The emission from this type of stove contains a small amount of carbon monoxide. This is normally converted rapidly into carbon dioxide, but if the burner of the gas chullah is not cleaned properly and the holes are blocked the emission of carbon monoxide will be high.

Melia et $a l^{818}$ have reported a higher prevalence of respiratory symptoms and disease in children from homes where gas was used for cooking, which they thought was due to pollution of the indoor atmosphere by the products of gas combustion associated with gas cooking. Similarly, Comstock et al ${ }^{19}$ and Ware et $a l^{20}$ noted that gas cooking was related to an increased frequency of respiratory symptoms and impaired ventilatory function.

This study was concerned with acute effects and it has shown that cooking with three different cooking fuels produces unacceptable indoor air pollution as indicated indirectly by blood carboxyhaemoglobin concentrations. The encouragement of proper cleaning of stove vents and the provision of adequate ventilation in kitchens could prevent some respiratory illness in developing countries.

1 Samet JM, Marbury MC, Spengler JD. Health effects and source of indoor air pollution. Part I. Am Rev Respir Dis 1987;136:1486-508.

2 Samet JM, Marbury MC, Spengler JD. Health effects and source of indoor air pollution. Part II. Am Rev Respir Dis 1988;137:221-42.

3 Dekoning HW, Smith KR, Last JM. Biomass fuel combustion and health. Bull WHO 1985;63:11-26.

4 Padmavati S, Arora R. Sex difference in chronic corpulmonale in Delhi. Br J Dis Chest 1976;70:251-9.

5 Malik SK. Exposure to domestic cooking fuels and chronic bronchitis. Indian J Chest Dis Allied Sci 1985;27:171-4.

6 Pandey MR. Domestic smoke pollution and chronic bronchitis in a rural community of hill region of Nepal. Thorax 1984;39:337-9.

7 Goldstein BD, Melia RJW, John HH. The relationship between respiratory illness and use of gas for cooking. II Factors affecting nitrogen dioxide levels in the home. Int Epidemiol 1979;8:339-45.

8 Melia RJW, Florey C du V, Chinn S. The relationship between respiratory illness in primary school children and use of gas for cooking. Int J Epidemiol 1979;8:333-8.

9 Keller MD, Lanese RR, Mitchell RI, Cote RW. Respiratory illness in households using gas and electricity for cooking. I. Survey of incidence. Environ Res 1979;19:495-503.

10 Keller MD, Lanese RR, Mitchell RI, Cote RW. Respiratory ilness in households using gas and electricity for cooking. II. Symptoms and objective findings. Environ Res 1979; 19:504-15.

11 Bhambi PN, Kambo KS, Arora AL. Domestic air pollution. Journal of the Air Clean Association of Japan 1975;13 54-60.

12 Spengler JD, Ferris BJ Jr, Dockery DW, Spezer PE. Sulphur dioxide and nitrogen dioxide levels inside and outside homes and the implications on health effects research. Environ Sci Technol 1979;13:1276-80.

13 Cleary GJ, Blackburn CRB. Air pollution in native huts in the highlands of New Guinea. Arch Environ Health 1968;17:785-94.

14 National Institute of Occupational Health. Domestic source of air pollution and its effects on respiratory system of housewives in Ahmedabad. Annual Report 1982. Ahmedabad: National Institute of Occupational Health, 1983:32-42.

15 Behera D, Dash S, Malik SK. Blood carboxyhaemoglobin levels following acute exposure to smoke of biomass fuel Indian J Med Res 1988;88:522-4.

16 Sakata M, Yoshida A, Haga M. Simple determination of carboxyhaemoglobin by double wave length spectrophotometry of absorbance difference and the comparison with gas chromatographic method. Forensic Sci Int 1983, 21:187-95.

17 Dary O, Pineda O, Belizan JM. Carbon monoxide contamin ation in dwelling in poor rural areas of Guatemala. Bull Environ Contam Toxicol 1981;26:24-30.

18 Melia RJW, Florey C du V, Altman DG, Swan AV. Association between gas cooking and respiratory disease in children. Br Med J 1977;ii:149-52.

19 Comstock GH, Meyer MB, Helsing KJ, Tuekman MS. Repeated effects of household exposure to tobacco smoke and gas cooking. Am Rev Respir Dis 1981;124:143-8.

20 Ware KH, Dockery DW, Spiro A, Speizer FE, Forris BG Passive smoking, gas cooking and respiratory health of children living in six cities. Am Rev Respir Dis 1984; 129:366-76. 


\section{LETTERS TO THE EDITOR}

\section{Vocal cord dysfunction and wheezing}

We read with interest the editorial by Drs J Goldman and M Muers (June 1991;46: 401-4). Although we agree with most of the review, we would disagree with their comments on hypoxaemia. They state that absence of hypoxaemia in vocal cord dysfunction helps to differentiate this condition from acute asthma.

We have seen two cases ourselves ${ }^{1}$ where hypoxaemia is a feature of vocal cord dysfunction. In one case the hypoxaemia (arterial oxygen tension $\mathrm{PaO}_{2}$ ) $79 \mathrm{~mm} \mathrm{Hg}$ with $100 \%$ inspired oxygen) and the induced "wheeze" were immediately relieved by intubation without recourse to assisted ventilation. On another occasion a similar effect was produced by the administration of a small dose of anaesthetic.

Nolan et al $1989^{2}$ report four patients, three of whom had demonstrable hypoxaemia during an acute episode $\left(\mathrm{PaO}_{2} 8 \cdot 45,5 \cdot 18\right.$, and $6.1 \mathrm{kPa}$ respectively). Appelblatt et al $1981^{3}$ report three patients who had hypoxaemia during an acute attack $\left(\mathrm{PaO}_{2} 50,52\right.$, and $44 \mathrm{~mm} \mathrm{Hg}$ ). Finally, in the report by Christopher et al $1983^{4}$ cited in the editorial the alveolar-arterial oxygen tension gradient was reported as normal in all five patients yet two young and apparently otherwise fit subjects had a $\mathrm{PaO}_{2}$ below $70 \mathrm{~mm} \mathrm{Hg}$.

We conclude that the comments regarding hypoxaemia are inaccurate and may lead to inappropriate management. As the authors point out, failure to make the correct diagnosis could result in potentially harmful iatrogenic complications.

Thus in our experience and that of other authors the presence of abnormal blood gases does not exclude a diagnosis of vocal cord dysfunction. We would however support the second summary conclusion, that any acute attack should be treated as asthma unless or until there is objective evidence to the contrary.

R McL NIVEN CAC PICKERING

Department of Thoracic and Occupational Medicine, Wythenshazve Hospital Manchester M23 9LT

1 Niven RMcL, Roberts T, Pickering CAC, Webb AK. Functional upper airways obstruction presenting as asthma. Respir Med (in press).

2 Nolan NT, Gibney N, Brennan N, FitzGerald MX. Paradoxical vocal cord motion syndrome in asthma. Thorax 1985;40:689.

3 Appelblatt NH, Baker SR. Functional upper airway obstruction, a new syndrome. Arch Otolaryngol 1981;107:305-7.

4 Christopher KL, Wood RP, Eckert RC, Blage FB, Raney RA, Souhrada JF. Vocal-cord dysfunction presenting as asthma. $N$ Engl $J$ Med 1983;308:1566-70.

AUTHORS' REPLY We wish to thank Drs Niven and Pickering for their interest in our paper. We consider that our views on patients with vocal cord dysfunction and wheezing are in fact quite similar. There is no doubt that hypoxaemia can occur in association with this syndrome, but we believe this to be the exception and not the rule. We did in fact state that hypoxaemia had occurred in the patients of Appelblatt et al (their reference 3). We still believe that the absence of hypoxaemia is usually helpful in differentiating vocal cord dysfunction from acute severe asthma. The presence of hypoxaemia does not, however, exclude vocal cord dysfunction. When faced with a wheezing hypoxaemic patient we feel it safest to recommend treatment for asthma, though this policy will very occasionally lead to unnecessary treatment. Physicians attending patients in whom they have diagnosed vocal cord dysfunction and who subsequently present with hypoxaemia may be confident enough to "administer a small dose of anaesthetic" but we believe that this advice cannot be given in an editorial to those less familiar with the condition. We stand by our statement that hypoxaemia is a useful indication that asthma is likely to be genuine, although perhaps "in nearly all patients" might be added in anticipation of Dr Niven and colleague's case report.

JON GOLDMAN MARTIN MUERS Regional Respiratory Unit, Killingbeck Hospital, Leeds LS14 6UQ

Intercostal arteriovenous fistula due to pleural biopsy

Dr J-H Lai et al report the development of a traumatic arteriovenous fistula after closed pleural biopsy (December 1990;45:976-8). In $1960 \mathrm{~J}$ Elkington and I reported a suspected arteriovenous aneurysm of intercostal vessels following simple pleural aspiration in a hypertensive young woman (Thorax $1960 ; 15: 266-7)$. But when the pleural cavity was later exposed during a Smithwick operation for sympathectomy the murmur was found to be due to a small traumatic arterial aneurysm only. Clearly the cutting edge of an aspirating needle is sufficient to induce such a lesion if it is inappropriately directed.

JBL HOWELI Medicine 1 General Hospital Southampton SO9 $4 X Y$

AUTHORS' REPLY Abnormal communications between arteries and veins may arise from rupture of an arterial aneurysm into the adjacent vein, developmental defects, inflammatory necrosis of adjacent vessels, and penetrating injuries that pierce the wall of artery and vein.' The Cope needle used for pleural biopsy and the common needle used for aspiration may all cause this if they are inappropriately introduced. An arteriovenous fistula due to rupture of an arterial aneurysm into the adjacent vein may take longer and depend on different mechanisms from those of fistulas due to penetrating injuries through the artery and vein. In our case we clearly showed the intercostal vein in the early arterial phase as well as a pseudoaneurysm formation. Isolated arterial aneurysm can not therefore be the cause. Nevertheless, we agree that the cutting edge of an aspirating needle inappropriately directed is sufficient to induce such a lesion. When we presented our case to our Chest Medicine Society no one had had a similar experience. Thus although traumatic arterial aneurysm or arteriovenous aneurysm may occur after invasive procedures they appear to be rare.

JENN-HAUNG LAI SHANG-JYH KAO CHIEN-YEH SHEN Division of Chest Medicine, Department of Internal Medicine, Tri-Service General Hospital, 622 Ting Chow Road, Taipei, Taiwan, Republic of China
1 Cotran RS, Kumar V, Robbins SL. Robbins Pathologic basis of disease. Philadelphia: 4th ed. Saunders, 1989:556.

BOOK NOTICE

Clearing the Air. A Guide for Action on Tobacco. M Raw, $P$ White, A McNeill. (Pp 151; £6.95.) London: British Medical Association for the World Health Organisation Regional Office for Europe, 1990. ISBN 0727902873

In the foreword to this wonderful book we are reminded that "Tobacco kills worldwide more than 2.5 million people prematurely every year. This is an appalling, almost unimaginable toll of suffering and death, representing a waste of human resources which ought to be unacceptable in a civilised society." The authors of this book then seek to enthuse, inform, and encourage their readers in the struggle against tobacco. They are remarkably successful in this aim. Most of the book is taken up by 10 "case studies" of initiatives, policies, and events that have shaped recent smoking control history. The topics include the enormously influential compilation of statistics of smoking related diseases in the United Kingdom called The Big $K i l l$, with the numbers of affected individuals broken down according to individual health authorities and parliamentary constituencies, and the shameful episode of Shoal Bandits (when the Government subsidised a new tobacco factory in Scotland, built by US Tobacco to manufacture oral tobacco snuff). Some of the case histories are an inspirationfor example, the Victorian Tobacco Act-and others rather depressing - for example, the voluntary agreement between the tobacco industry and the Government. Throughout this book there is much good advice on how things can be achieved, and the names and contact addresses of all of the key individuals and organisations are listed. There is also an enormously useful book list. This book is written with an authority that reflects the direct experience and commitment of the authors working in the field of tobacco control. In my view it should be required reading for anyone interested in combating smoking.-JM

\section{CORRECTIONS} Carboxyhaemoglobin in women
exposed to different cooking fuels

In the paper by $\mathrm{Dr} D$ Behera and others (May $1991 ; 46: 344-6)$, on page 344 in line 13 of the abstract, $7.52 \%$ should be $7.49 \%$, and on page 345 in line 10 of "Results" ( $p=0.33)$ should appear after "users."

Prevalence of asthma among 12 year old children in New Zealand and South Wales: a comparative survey

In the paper by Dr DMJ Barry and others (June 1991;46:405-9) on page 407, column 1, line $17,3 \%$ should be $31 \%$. 